\title{
The knowledge and expectations of parents about the role of antibiotic treatment in upper respiratory tract infection - a survey among parents attending the primary physician with their sick child Shlomo Vinker*, Adi Ron and Eliezer Kitai
}

Address: Department of Family Medicine, Tel Aviv Sackler school of Medicine, Tel Aviv, Israel

Email: Shlomo Vinker* - vinker01@inter.net.il; Adi Ron - yoninadi@netvision.net.il; Eliezer Kitai - drkitai@netvision.net.il

* Corresponding author

This article is available from: http://www.biomedcentral.com/I47/-2296/4/20

(C) 2003 Shlomo et al; licensee BioMed Central Ltd. This is an Open Access article: verbatim copying and redistribution of this article are permitted in all media for any purpose, provided this notice is preserved along with the article's original URL.

\begin{abstract}
Background: Upper respiratory tract infections (URTI) are common. The etiologic factor is usually viral, but many physicians prescribe antibiotics. We aimed to evaluate parents' expectations of and knowledge about the role of antibiotics in childhood URTI.

Methods: The study was conducted in thirteen primary care pediatric clinics. Parents of children aged 3 months to 6 years who attended with URTI symptoms were included when it was the first attendance in the current illness. Questionnaire about the current illness, reasons for attending and expectations from the visit, knowledge about URTI was filled before the visit.

Results: In 122 visits the average age was $2.8 \pm 1.9$ years. The main reasons for the visit were to avoid complications (8I\%) and to be examined (78\%). Expected treatment was: cough suppressants (64\%), anti-congestants (57\%), paracetamol (56\%), natural remedies (53\%) and antibiotics $(25 \%)$. In $28 \%$ the child had received antibiotics in past URTI. Only $37 \%$ thought that antibiotics would not help in URTI and $27 \% \mathrm{knew}$ that URTI is a self-limited disease. $61 \% \mathrm{knew}$ that URTI is a viral disease. Younger parental age and higher education were associated with lower expectations to receive antibiotics $(p=0.01, p<0.005$ respectively). While previous antibiotic treatment $(p<0.00 \mathrm{I})$, past perceived complications $(p=0.05)$ and the thought that antibiotics help in URTI $(p<0.00 I)$ were associated with a greater expectation for antibiotics.
\end{abstract}

Conclusions: A quarter of the parents attending the physician with URTI are expecting to get antibiotics. Predictors were lower education, older parental age, receiving antibiotics in the past and the belief that antibiotics help in URTI.

\section{Background}

Patients with Upper Respiratory Tract Infection (URTI) constitute a major part of the primary care physician's workload during the winter months [1]. In most cases the etiologic factor is viral and there is no need for antibiotic treatment $[2,3]$. Many physicians continue to prescribe antibiotic treatment for URTI, knowing that antibiotics do not help viral infection and despite the development of resistant bacterial strains. 
The factors that influence physicians decision to prescribe antibiotics for URTI are: suspected bacterial disease, the fear that a viral infection will lead to a secondary bacterial infection and doctors' belief that the patient expects to receive antibiotics for his illness [4].

URTI is the most common infectious disease in children, with five to eight episodes each year 1. Previous studies in the USA and UK had shown that more than 30\% of parents expected their child with URTI to receive antibiotic treatment at the first visit to the pediatrician $[5,6]$. Mangione-Smith et al noted that fifty percent of parents expressed a pre-visit expectation for antibiotics [7]. The reasons were: the fear of a severe illness which requires antibiotic treatment, the belief that antibiotics are the treatment of choice for URTI, relieve symptoms and shorten the duration of the disease 5. Parental expectation to receive antibiotics was found to be a major factor influencing the overuse of antibiotics [8]. Mangione-Smith et al noted that physicians' perceptions of parental expectations for antibiotics was the only significant predictor of actual prescribing of antibiotics for conditions of presumed viral etiology [9]. When physicians thought a parent wanted antibiotics, they prescribed them $62 \%$ of the time versus $7 \%$ of the time when they did not think the parent wanted antibiotics. In addition, when physicians thought the parent wanted an antimicrobial, they were also significantly more likely to give a bacterial diagnosis (70\% of the time versus $31 \%$ of the time].

Using clinical vignettes, Schwartz et al [10] found that the main reasons given for prompt antibiotic therapy for purulent rhinitis were [1] the belief that many untreated patients would develop persistent purulent nasal drainage, [2] concern that acute otitis media would develop, [3] pressure from mothers to prescribe an antibiotic and/or [4] the desire to allow employed parents to return to work earlier.

Stivers et al revealed an incongruity between parents' reported expectations, their communication behaviors, and physicians' perceptions of parents' expectations [11]. Though it seems that physicians act according to parents' expectations by prescribing antibiotic treatment, it does not influence parents' satisfaction from the encounter [12]. Spending more time in explaining the nature of the disease and reassuring that it's not a severe one seem to be much more important $[4,13]$. Parents indicated that they would be satisfied with the medical visit even if antibiotics were not prescribed, provided the physician explained the reasons for the decision [8].

Following a public campaign in Israel against antibiotic use in URTI we aimed to evaluate parents' expectations, beliefs and knowledge about the role of antibiotics in childhood URTI.

\section{Methods}

The study was conducted in thirteen urban primary care pediatric clinics in the winter of 2000/2001. It followed a public campaign against antibiotic use in URTI that took place that winter. The campaign used the public media (written and electronic) as well as pamphlets and posters in primary care clinics. It was focused mainly on two items: URTI is a viral disease and antibiotics are not the solution. In Israel most of the children in the urban setting are being treated by pediatritians and only in rural regions by a general practitioner. In each clinic ten suitable consecutive cases were enrolled by a family practice resident (not working in the same clinic). The residents recruited participants by contacting the parents of children aged 3 months to 6 years in the waiting room according to the appointments list. Children presented with URTI symptoms (nasal congestion, cough, fever and sore throat) were included, only if it was their first attendance in the current illness.

Visits due to fever lasting more than 7 days, chronic diseases, other symptoms such as earache, or children who came without one of their parents were excluded from the study.

The parents filled in a questionnaire, which was handed out by before entering the physicians' office. The resident was available to answer any questions or misunderstandings.

The questionnaire included three parts:

The first part included demographic data about the child and parents, parents' occupation and educational background, and the caregiver who takes care of the child during health and illness.

The second part inquired about the current illness: duration of symptoms, severity of illness in parents' view, symptoms, reasons for current visit and data about past antibiotic treatment.

In the third part we asked about parents' knowledge and health beliefs -

What is the treatment of choice for the current illness?

Does antibiotic treatment help?

Do you think that URTI is a self-limited disease? 
Table I: Socio-demographic data of Parents in I 22 visits of children with URTI

\begin{tabular}{ll}
\hline Escort parent & Mother $-82 \%$ \\
& Father $-18 \%$ \\
Age of parents (years, mean + SD, range) & Escort parent $-30.6 \pm 5.5(20-47)$ \\
& Other parent $-32.8 \pm 5.6(20-50)$ \\
Occupation - full or part time & Escort parent $79.6 \%$ \\
& Other parent $76.7 \%$ \\
Education (years, mean + SD) & Escort parent $-14.1+2.4$ \\
Single parent families & Other parent $-14.3+2.5$ \\
\hline
\end{tabular}

Table 2: Reasons for physician referral and expected treatment by Parents in I 22 visits of children with URTI*

\begin{tabular}{|c|c|}
\hline Reason for referral & Rate (percent) \\
\hline To avoid complications & $83 \%$ \\
\hline Just to be checked & $79 \%$ \\
\hline To get medications & $54 \%$ \\
\hline Administrative & $9 \%$ \\
\hline Others & $4 \%$ \\
\hline Expected treatment & Rate (percent) \\
\hline Cough suppressant & $67 \%$ \\
\hline Anticongestants & $60 \%$ \\
\hline Paracetamol & $56 \%$ \\
\hline Alternative medications & $55 \%$ \\
\hline Antibiotics & $24 \%$ \\
\hline
\end{tabular}

*There can be more than one reason for referral or expected treatment for each visit.

Do you think there could be harm from antibiotic treatment?

What is the etiologic agent of URTI?

Do you think that natural remedies are useful?

\section{Statistical methods}

parents' answers were entered to an electronic spreadsheet. To compare percentage between two groups we used $\chi^{2}$ test. Linear variables were assessed by t-test to compare two groups and by ANOVA for comparison of more than two groups.

\section{Results}

The study included 122 visits (for a response rate of 93\%) from 13 primary care pediatric clinics. The childrens' age ranged from 3 months to 6 years (average $2.8 \pm 1.9$ ), 55\% were boys. The attending child was the only child in $30 \%$ of cases, one of two in $42 \%$, one of three in $19 \%$, and one of four or more in the remaining cases. In $79 \%$ of cases the attending child was the youngest in the family. In $81.5 \%$ the child attended a day care center.
In $82 \%$ of the visits the escorting parent was the mother, table 1 shows the socio-demographic data of the parents. In case of an illness the child would be taken care by one of the parents in 57\%, grandparents $13 \%$, parents/grandparents $19 \%$ or a nanny $7 \%$.

Symptoms duration of the current illness was less than 24 hours in $47 \%$ of cases, and in only $23 \%$ lasted more than 4 days. $69 \%$ of the parents defined their child's illness as mild.

The symptoms included: rhinorrhea (87\%) cough $(87 \%)$, and fever (64\%). Table 2 shows the reasons for the visit and the expected treatment. In $28 \%$ of the cases the child received antibiotics in a past URTI and according to their parents 38\% had complications after a past URTI. $24 \%$ of the parents thought that antibiotic treatment was appropriate for the current illness.

Table 3 shows parents' answers to some factual questions, about antibiotic treatment in URTI. 
Table 3: Parents' answers to some knowledge questions, about antibiotic treatment in I 22 visits of children with URTI.

\begin{tabular}{lc}
\hline Question & Rate of "yes" answer (percent) \\
\hline Antibiotics don't help in URTI & $37 \%$ \\
The illness is self-limited & $28 \%$ \\
Misuse of antibiotics may cause harm & $78 \%$ \\
URTI is usually caused by a virus & $60 \%$ \\
Alternative medications may help & $63 \%$ \\
\hline
\end{tabular}

Younger parents had a lower expectation for antibiotic treatment (escort parent age $30.5+5.2$ vs. $31.2+6.2, \mathrm{p}=$ NS, other parent age $32.4+5.3$ vs. $37.4+7.4 \mathrm{p}=0.01$ ). Higher educated parents had a lower expectation for antibiotic treatment (escort parent years of education $14.5+2.5$ vs. $12.8+2.1, \mathrm{p}=0.001$, other parent years of education $14.9+2.4$ vs. $13.2+2.3 \mathrm{p}<0.005)$.

There was no association between parental socio-demographic characteristics and other treatments (paracetamol, anticongestants, cough suppressants or natural remedies).

Antibiotic treatment in previous URTIs was associated with a greater expectation for antibiotic treatment $54 \%$ of the previously treated expected antibiotics vs. 19\% among previously untreated, $\mathrm{p}<0.005)$. The experience of past complications after an URTI was associated with a greater expectation for antibiotic treatment $(58 \%$ vs. $33 \%, \mathrm{p}=$ $0.04)$.

Parents that answered a positive answer to the statement "antibiotics don't help in this kind of an illness" had a lower expectation for antibiotic treatment (43\% vs. 15\% p $=0.002$ ). Parents that answered a positive answer to the statement "this disease is a self-limited one", had a lower expectation for antibiotic treatment ( $8 \%$ vs. $35 \%$, p = $0.01)$

There was no association between expectation to get antibiotics and the statements "antibiotics misuse can cause harm" and "URTI is usually a viral disease".

\section{Discussion}

Our findings do not support the common belief among physicians, which in cases of URTI parents expect is to receive antibiotic treatment [1]. We found that only $24 \%$ of the parents thought that antibiotics are part of the treatment of their sick child, while more than half expected to get symptomatic relief or natural remedies.

Adults expect to get antibiotic treatment for URTI in 50$65 \%$ of cases $[4,5]$. Braun et al [3] reported a lower rate, only 30\% while Mangione-Smith et al reported 50\% expectation for antibiotics [7]. It is worth noting that the exclusion of children presenting with ear pain in our study may impact the lower parental expectations for antibiotic treatment we found in comparison with others.

It seems therefore that in cases of URTI the reasons for attending the pediatrician may not be different from those of adult visits $[11,12]$. Cowan examined URTI patients' expectations from the encounter5. She found that the major reason for the visit was to get reassurance that it is not a serious disease. The actual treatment given by the physician did not influence patient satisfaction from the visit and did not reduce the chance of a recurrent visit $[4,13]$. We found that the major reasons for referral where to be examined by a physician and to prevent future complications, similarly to the findings of Braun et al [5]. Hamms et al [4] noted that listening to the patient and spending time explaining the nature of the disease raises patient satisfaction.

Braun found a correlation between the expectation to get antibiotic treatment and parents' occupation. Parents who worked full time had higher expectation to get antibiotic treatment, maybe assuming that it will shorten disease duration and therefore getting back to work earlier [5]. Such a correlation was not found in our study. It maybe because of greater support from the extended family or the fact that work absence due to child's illness is normative and have a legal basis in labor regulations in Israel.

We found a lower expectation rate for antibiotics among younger parents and among more highly educated. It seems that the campaign held in Israel against the use of antibiotics for URTI had a higher impact on young and educated parents.

The study of Braun et al showed a higher expectation rate for antibiotics in parents who defined their child's illness as serious, felt the disease was lasting too long, or wanted a quick relief of symptoms [5]. In our study most parents defined their child's illness as mild and of short duration in contrast to other studies, this could explain the fact we did not found correlation between expectations for antibi- 
otic treatment and these variables. The short duration of illness is with concordance with the highly available primary care service in Israel and the competition between HMOs. Waiting another 2-3 days before a visit would result in resolution of the milder episodes of URTI.

Parents do not expect antibiotic treatment in most cases and physicians know that antibiotics do not help in treating URTI. Why then physicians continue to prescribe antibiotics and how can we lower the antibiotic overuse for URTI? [1,6,14]. It seems that the medical community encourages patients to visit the physician and to expect antibiotic treatment in cases of URTI 15. Physicians think patients expect to get antibiotic treatment, but this assumption is incorrect in most cases. Physicians cannot predict patients' expectations correctly [1].

Physicians' behavior, in cases of URTI, influences the parents' position. We found that past antibiotic prescription raised expectation for antibiotic treatment in the current visit. That finding was demonstrated in previous works as well $[1,16]$. There is a need, therefore, to understand physicians' beliefs and behaviors and to find ways to change them. Physicians asserted that their own antibiotic prescribing could be safely reduced [8]. Parental expectation to receive antibiotics was a major factor influencing their overuse of antibiotics8. On the other hand Cockburn et al found that although patients brought expectations to the consultation regarding medication, the doctors' opinions about their expectations were the strongest determinants of prescribing [9].

The differences in physician and parent perceptions about antibiotic overuse suggests that educational efforts to narrow this communication gap will be important for improving antibiotic use. Parents perceived as expecting antibiotics may be seeking reassurance that their child is not seriously ill or that they were correct to obtain medical care. Physicians were significantly more likely to perceive parents as expecting antibiotics if they used certain communication behaviors [11]. Further research is needed to better understand physician beliefs and behaviors and ways to change them.

Health beliefs and parents' knowledge regarding URTI influenced their expectation for antibiotic treatment. We found that attitudes such "antibiotics do not help in such illnesses" and "illnesses like this are self limited", were associated with lower expectation for antibiotic treatment. Emphasizing and strengthening these beliefs, as well as explaining the nature of the disease and that antibiotics can cause complications, could contribute to the success of future campaigns. Providing patients and parents with this information will help doctors to give better medical treatment without prescribing unnecessarily antibiotic treatment for URTI. Further research should focus on evaluation of parents' expectations and effective ways to educate the parent about appropriate use of antibiotics in treatment for URTI.

\section{Conclusions}

A quarter of the parents attending the physician with URTI expected to get antibiotics. Predictors were lower education, older parental age, and receiving antibiotics in the past and the belief that antibiotics help in URTI. It seems that strengthen the positive patient's beliefs and consider intervention to change physicians' prescribing habits may contribute to the reduction of antibiotic use in URTI.

\section{Competing intersts}

None declared.

\section{Authors' contribution}

SV conceived and designed the study, participated in the collection, analysis, statistical analysis and interpretation of data and drafted the manuscript. RA participated in the design of the study, analysis and interpretation of data and draft of the manuscript. EK participated in the design of the study and in the collection of data and draft of the manuscript. All authors read and approved the final manuscript.

\section{Acknowledgments}

Special thanks to: Ezra V, Hason I, Mendelson A, Uziel N, Dorfman I, Tamir $\mathrm{N}$, Bro-Aloni T, Vinker R, who all helped with initiating the idea and collecting the data for the research.

\section{References}

I. Bauman KA: The family physician's reasonable approach to upper respiratory tract infection care for this century. Arch Fam Med 2000, 9:596-7.

2. Orr PH, Scherer K, Macdonald A, Moffatt ME: Randomized placebo-controlled trials of antibiotics for acute bronchitis: a critical review of the literature. J Fam Pract 1993, 36:507-I2.

3. Gonzales R, Malone DC, Maselli JH, Sande MA: Excessive antibiotic use for acute respiratory infections in the United States. Clin Infect Dis 200I, 33:757-62.

4. Hamm RM, Hicks RJ, Bemben DA: Antibiotics and respiratory infections: are patients more satisfied when expectations are met? Fam Pract 1996, 43:56-62.

5. Braun BL, Fowles JB: Characteristics and experiences of parents and adults who want antibiotics for cold symptoms. Arch Fam Med 2000, 9:589-95.

6. Palmer DA, Bauchner H: Parents' and physicians' views on antibiotics. Pediatrics 1997, 99:E6.

7. Mangione-Smith R, McGlynn EA, Elliott MN, McDonald L, Franz CE, Kravitz RL: Parent expectations for antibiotics, physician-parent communication, and satisfaction. Arch Pediatr Adolesc Med 200I, I 55:800-6.

8. Barden LS, Dowell SF, Schwartz B, Lackey C: Current attitudes regarding use of antimicrobial agents: results from physician's and parents' focus group discussions. Clin Pediatr (Phila) 1998, 37:665-7|.

9. Cockburn J, Pit S: Prescribing behaviour in clinical practice: patients' expectations and doctors' perceptions of patients' expectations - a questionnaire study. BMJ 1997, 3 I 5:520-3.

10. Schwartz RH, Freij BJ, Ziai M, Sheridan MJ: Antimicrobial prescribing for acute purulent rhinitis in children: a survey of pedia- 
tricians and family practitioners. Pediatr Infect Dis J 1997, 16:185-90.

II. Stivers T, Mangione-Smith R, Elliott MN, McDonald L, Heritage J: Why do physicians think parents expect antibiotics? What parents report vs what physicians believe. J Fam Pract 2003, 52:140-8.

12. Mangione-Smith R, McGlynn EA, Elliott MN, Krogstad P, Brook RH: The relationship between perceived parental expectations and pediatrician antimicrobial prescribing behavior. Pediatrics 1999, 103:7II-8.

13. Cowan PF: Patient satisfaction with an office visit for the common cold. I Fam Pract 1987, 24:4I 2-3.

14. Nyquist AC, Gonzales R, Steiner JF, Sande MA: Antibiotic prescribing for children with colds, upper respiratory tract infections, and bronchitis. JAMA I998, 279:875-7.

15. Skull SA, Ford-Jones EL, Kulin NA, Einarson TR, Wang EE: Childcare center staff contribute to physician visits and pressure for antibiotic prescription. Arch Pediatr Adolesc Med 2000, I 54:I80-3.

16. Watson RL, Dowell SF, Jayaraman M, Keyserling H, Kolczak M, Schwartz B: Antimicrobial use for pediatric upper respiratory infections: reported practice, actual practice, and parent beliefs. Pediatrics 1999, 104:125I-7.

\section{Pre-publication history}

The pre-publication history for this paper can be accessed here:

http://www.biomedcentral.com/1471-2296/4/20/prepub

Publish with Biomed Central and every scientist can read your work free of charge

"BioMed Central will be the most significant development for disseminating the results of biomedical research in our lifetime. "

Sir Paul Nurse, Cancer Research UK

Your research papers will be:

- available free of charge to the entire biomedical community

- peer reviewed and published immediately upon acceptance

- cited in PubMed and archived on PubMed Central

- yours - you keep the copyright 